\title{
A "naturalização de massa" na Romênia e a "venda" da Nacionalidade de Estados-membros da União Europeia: reflexões sobre o uso político e econômico do instituto jurídico da nacionalidade
}

\author{
The "mass naturalization" in Romania and the "sale" of the Citizenship of \\ Member States of the European Union: reflections about the political and \\ economic use of the legal institution of nationality
}

\author{
Aline Beltrame de Moura \\ Universidade Federal de Santa Catarina, Florianópolis - SC, Brasil \\ Complexo de Ensino Superior de Santa Catarina, Florianópolis - SC, Brasil
}

Resumo: O tradicional instituto jurídico da nacionalidade vem sofrendo relevantes transformações, principalmente diante dos mais recentes fenômenos observados na condução de políticas estatais voltadas para a reforma das legislações sobre nacionalidade com o escopo de introduzir inusitados critérios para a atribuição do status $c i$ vitatis aos estrangeiros interessados. $\mathrm{O}$ presente estudo pretende, assim, verificar se, e em qual medida, as políticas implementadas por Estados-membros da União Europeia, destinadas a atribuir a nacionalidade por meio de "naturalizações de massa" ou mesmo da sua mera "venda", não se tornem formas de utilizar esse instituto jurídico para fins políticos e econômicos em nítido contraste com normas europeias e internacionais.

Palavras-chave: Atribuição da Nacionalidade. Políticas Estatais. União Europeia.

Recebido em: 07/01/2015

Revisado em: 10/09/2015

Aprovado em: 08/10/2015
Abstract: The traditional legal institution of nationality has been undergoing relevant transformations, mainly due to the recent phenomenon observed in the operation of state policies focused on the reform of laws regulating nationality, aimed at introducing different criteria for the assignment of status civitatis to foreigners interested in it. The present study intends to verify if, and to what extent, the policies implemented by Member States of the European Union, designed to grant nationality through "mass naturalization" procedures or even its mere "sale", are not correct ways to use this legal institution for political and economic ends in a sharp contrast with the European and international standards.

Keywords: Nationality Granting. State Policies. European Union. 
A "naturalização de massa" na Romênia e a "venda" da Nacionalidade de Estados-membros da União Europeia: reflexões sobre o uso político e econômico do instituto jurídico da nacionalidade

\section{Introdução}

No contexto de um processo de integração regional complexo e altamente avançado como aquele da União Europeia, a escolha por determinada orientação de políticas nacionais em relação a uma dada matéria pode se mostrar relevante também no âmbito supranacional, a partir do momento que venha a ocasionar implicações diretas ou indiretas nos interesses dos demais Estados-membros. Nesse sentido, a regulamentação dos critérios de atribuição da nacionalidade por parte das legislações internas destes Estados deve respeitar os princípios e as normas do ordenamento jurídico da União, haja vista os inevitáveis efeitos transfronteiriços que a disciplina da nacionalidade pode ocasionar nos demais Estados-membros.

É notório que ao conceder a nacionalidade a um determinado sujeito, ele adquire automaticamente a cidadania da União europeia e, assim, a titularidade de inúmeros direitos que se repercutem diretamente nos interesses de outros Estados-membros, nomeadamente os decorrentes do exercício da liberdade de circulação e de residência no espaço territorial europeu. Desse modo, compreende-se por qual motivo a utilização de certos critérios de atribuição da nacionalidade possa provocar consequências além do plano interno, adentrando na esfera de atuação do direito e da política da União Europeia e, por conseguinte, da competência jurisdicional do Tribunal de Justiça comunitário.

Partindo, portanto, de tais premissas, o presente estudo pretende verificar se, e em qual medida, a chamada "naturalização de massa" ocorrida na Romênia, se configure como uma resposta à política ostensiva de influência russa nas regiões que haviam pertencido à antiga União Soviética, em especial na Moldávia. Num segundo momento, pretende-se analisar eventuais incompatibilidades de certas políticas de naturalização que concedem, com extrema facilidade, o privilégio da nacionalidade a estrangeiros que literalmente "comprem" a nacionalidade de um Estado-membro através de investimentos externos ou mesmo por meio do pagamento de um determinado montante em dinheiro. O escopo final é verificar se tanto a política de "naturalização de massa" romena quanto a "venda" da nacionalidade realizada recentemente por outros países, como 
Portugal, Áustria, Malta e Chipre estejam, ou não, em contraste com o ordenamento jurídico e as políticas supranacionais da União Europeia.

Depreende-se, assim, como as questões que envolvam o tradicional instituto da nacionalidade ainda se apresentem como atuais e sujeitas às vicissitudes contextuais e de toda sorte pelas quais passam os países na contemporaneidade, notadamente aquelas de cunho político e econômico, fato que exige um estudo constante e rigoroso acerca das inovações nesta matéria.

\section{Precedentes Históricos da Formação da Nação Romena}

A fim de compreender as questões jurídicas que envolvem os motivos pelos quais foram, na atualidade, privilegiados certos critérios de atribuição da nacionalidade romena em detrimento de outros, imprescindível se torna realizar uma breve análise dos precedentes históricos relativos à formação da chamada Nação romena.

A Romênia foi formada em 1858, durante o Congresso de Paris, por meio da unificação dos Principados da Moldávia e da Valáquia, alcançando a sua completa independência em 1878 no Congresso de Berlim. A denominação "Grande Romênia" surgiu após a Primeira Guerra Mundial por meio de uma importante expansão territorial que fez duplicar a sua superfície inicial. Com a Declaração de Alba Iulia, de $1^{\circ}$ de dezembro de 1918, institui-se a nova Romênia que compreendia além dos principados da Moldávia e da Valáquia, também Banato, Transilvânia, Bessarábia, Bucovina, Maramures (LEONCINI, 2007).

Nessa época, segundo Constantin Iordachi (2006), aproximadamente $28 \%$ da população era composta por minorias nacionais (húngaros, alemães, hebreus, ucranianos, russos), situação que acabou dificultando a criação de um Estado-nação homogêneo. No período posterior à Declaração de 1918, a Romênia iniciou uma intensa política de nacionalização. O país perdeu os territórios do Leste (Bessarábia e Bucovina) e, assim, uma considerável parte da população. Além disso, durante a época comunista, sob pressão soviética e por meio da presença militar, vigorou o princípio da autodeterminação nacional de Vladimir Lênin, impulsionando a atribuição de uma espécie de status autônomo às cidades habitadas por húngaros. 
Percebe-se, desse modo, como a herança histórica deixada pelas diferentes etnias acabou por influenciar de modo decisivo a política em matéria de nacionalidade, não somente na Romênia, mas também em grande parte dos Países que faziam parte do regime comunista, tais como Albânia, Bulgária, Hungria e Polônia. Muito embora nenhum destes países tenha sofrido modificações territoriais ou intensos movimentos migratórios após 1989, nos últimos anos todos têm realizado uma completa revisão das suas leis sobre nacionalidade. O principal objetivo destas reformas legislativas é, de um lado, refletir a nova realidade política destes Estados e, de outro, enfrentar as diferentes variações do território e de população que ocorreram no período que compreendeu a Segunda Guerra Mundial e aquele anterior à dissolução da União Soviética (IORDACHI, 2006).

Com relação ao caráter reparador de tais políticas, salienta Andre Liebich (2007, p. 27) que

[...] a peculiaridade dos novos Estados da União Europeia é que as leis sobre nacionalidade preveem disposições que foram elaboradas com a intenção de reparar os erros passados. A função compensatória ou reconstitutiva é particularmente forte em relação ao recente passado comunista, muito embora também alcance períodos mais remotos.

A Romênia, portanto, é um claro exemplo de país pertencente à ex-União Soviética que, com a queda do regime comunista, colocou em prática uma série de políticas destinadas à restauração do status quo ante, cujos conteúdos compreendiam tanto a reintegração dos direitos e dos bens de uma determinada categoria de indivíduos quanto a reconstrução do sentimento de pertença perdido no decorrer do tempo em razão das sucessivas alterações territoriais e de população.

Após décadas de isolamento político da diáspora e da proibição da dupla nacionalidade, muitos desses países retomaram as políticas de "positive discrimination" em relação aos seus "compatriotas" no exterior, salienta Iohana Iordachi (2006, p. 124). Além disso, nota-se que durante o regime comunista, as legislações sobre a nacionalidade na Romênia foram utilizadas como instrumento de repressão e de controle, tendo em 
vista que as autoridades controlavam rigorosamente as imigrações internas e monitoravam o movimento dos estrangeiros no território.

\section{A Política de "naturalização de massa" Como Forma de "res- tituição" da Nacionalidade Perdida e Consolidação do Poder Geopolítico}

Inicialmente, cumpre esclarecer que através da naturalização, o estrangeiro, que possui uma outra nacionalidade, ou o apátrida, pode adquirir a nacionalidade do país no qual se encontra, sempre que satisfaça todos os requisitos exigidos por lei. Segundo Jacob Dolinger (1997), a naturalização é um ato unilateral e discricional realizado pelo Estado no exercício da sua soberania. Completamente diferente é a questão da "naturalização em massa", em relação a qual se deve verificar se, e em qual medida, ela pode constituir um abuso de poder por parte do Estado à luz do ordenamento jurídico internacional e, principalmente, do direito da União europeia, como no caso ora em apreço.

$\mathrm{Na}$ tentativa de restabelecer a ideia de Nação romena, uma das principais medidas adotadas pelo governo foi a implementação da política de reconstrução da noção de pertença nacional, considerando que, principalmente nos anos quarenta do século passado, aconteceram diversas mudanças nos limites territoriais da região romena, fator considerado determinante para a dispersão da população. Visando minorar os efeitos decorrentes dessa dispersão, o governo romeno tem facilitado a "restituição" da nacionalidade a todos aqueles que a possuíam e que, em razão das citadas alterações territoriais, a tenham perdido. Cumpre recordar que os beneficiários de tal política são tanto os indivíduos que tenham perdido a nacionalidade em virtude das circunstâncias acima expostas como também os seus descendentes.

Essa política implicou uma grande (re)naturalização, sobretudo, dos habitantes da Moldávia e de algumas províncias da Ucrânia, privados da nacionalidade romena nos períodos entre 1940 e 1941 e posteriormente a 1944, isto é, logo após a ocupação soviética da Bessarábia e da Bucovina setentrional (IORDACHI, 2013). 
A "naturalização de massa" na Romênia e a "venda" da Nacionalidade de Estados-membros da União Europeia: reflexões sobre o uso político e econômico do instituto jurídico da nacionalidade

A democratização política, iniciada em 1989 com a queda do Muro de Berlim, teve um grande impacto na disciplina da nacionalidade, em particular, na redefinição dos seus critérios de atribuição. Nesse ponto, oportuno recordar que as bases legais da moderna nacionalidade romena foram definidas pelo respectivo Código Civil de 1865, cuja inspiração foi buscada no sistema jurídico francês disciplinado no Código Napoleônico de 1804. O princípio basilar para a atribuição da nacionalidade era, assim, o ius sanguinis, escolha legislativa que implicava uma política seletiva de naturalização dos estrangeiros no sentido de privilegiar aqueles que tinham nascido e crescido no país. Todavia, o modelo de inspiração francesa foi modificado em diversas oportunidades pela Romênia, tendo sido introduzidos outros critérios não previstos inicialmente pelo Code Civil, como o culto da religião cristã e a comprovação de possuir a etnia romena.

Atualmente em vigor, a Lei romena sobre a Nacionalidade de 1991 consagrou duas importantes inovações: a primeira refere-se à permissão concedida ao nacional romeno de possuir dupla nacionalidade e a segunda diz respeito à possibilidade de os indivíduos da antiga Grande Romênia readquirirem a nacionalidade romena. De fato, a citada lei prevê três possibilidades para a reaquisição do status civitatis romeno: a repatriação (art. 8), a (re)naturalização por solicitação sem repatriação (art. 11) e a recuperação da nacionalidade pelos ex-nacionais romenos que vivem no território da Grande Romênia que foram perdidos no período das duas Guerras Mundiais (art. 35). Tendo como base jurídica esta nova legislação e segundo pesquisas não oficiais, entre 1991 e 2000, o governo romeno teria concedido a sua nacionalidade para mais de 300 mil moldavos e estima-se que em 2003 cerca de $40 \%$ da população da Moldávia gozava da dupla nacionalidade de países como a Romênia, Bulgária, Israel ou Rússia (IORDACHI, 2006).

O fato que chama a atenção é a ausência da obrigação de residir na Romênia ou de ter que entrar no País para dar início ao procedimento de "reaquisição". Em comparação com um tradicional processo de naturalização, a restituição da nacionalidade para esta categoria de beneficiários observa um simples procedimento que poderia consistir no envio por correio da citada solicitação ou mesmo na presença de um terceiro junto às 
embaixadas ou aos consulados romenos no exterior. Segundo Constatntin Iordachi (2013), os interessados poderiam demonstrar a sua origem étnica mediante meros testemunhos ou certificados emanados pelas comunidades romenas no exterior, tendo que ulteriormente demonstrar o conhecimento básico da língua romena. Era uma prática conhecida como "reconhecimento" da nacionalidade.

Aos requerentes não era exigida a realização de uma entrevista oficial ou mesmo da presença pessoal do interessado em Bucareste, uma vez que o juramento de fidelidade poderia ser realizado junto às representações diplomáticas ou consulares da Romênia situadas no exterior. Até este ponto pode-se dizer que se trata de um procedimento comum praticado por diversos Estados no tocante à concessão da nacionalidade a indivíduos que residam no exterior. Porém, o que causa certa surpresa é o fato de existir um tratamento diferenciado dependendo da "categoria" de estrangeiro interessado. De fato, os requerentes que solicitavam o chamado "reconhecimento" da nacionalidade eram exonerados, por exemplo, do pagamento das taxas consulares e também das exigências do procedimento de naturalização que, ao invés, eram necessárias para a concessão da naturalização de um estrangeiro "tradicional".

No mais, ressalta-se que a aplicação desta lei teve vários períodos de suspensão entre dezembro de 2001 e setembro de 2007 em razão do grande número de solicitações (MARGIOTTA; VONK, 2010), sobretudo após a permissão dada aos nacionais romenos de circularem no espaço Schengen sem a necessidade de visto. Nesse sentido, as instituições da União Europeia manifestaram preocupação acerca do fato de que, no momento da adesão da Romênia ao bloco europeu, a sua política de restituição da nacionalidade "[...] poderia se tornar um portão incontrolável de acesso ao espaço Schengen por parte de cidadãos não-europeus e que isto teria o condão de suplantar as políticas migratórias restritivas [...]" (IORDACHI, 2013, p. 3) impostas pelo bloco regional no tocante à circulação de extracomunitários.

Essa "corrida" à nacionalidade romena, especialmente por parte dos moldavos, foi motivada também por outros acontecimentos ocorridos no início do século XXI. Dentre os quais, destaca-se o forte debate promovi- 
do pelos partidos políticos para que fosse designado o russo como língua oficial, muito embora a Constituição reconhecesse o moldavo como única língua oficial do Estado. O debate intensificou-se, pois, tecnicamente, o moldavo é considerado um dialeto romeno, levando também a Romênia a travar sérias discussões com a Rússia pelo domínio geopolítico da região.

Políticos moldavos, e também ucranianos, acusaram a Romênia de utilizar a questão da dupla nacionalidade como estratégia para aumentar a sua influência na região, com o objetivo de readquirir os territórios perdidos no passado. Por tais motivos, muitos acreditam que a política de nacionalidade adotada pela Romênia ao invés de buscar uma justiça retroativa e de integração acabou favorecendo o crescimento da instabilidade na região (IORDACHI, 2013). Nesse contexto, o governo da Romênia emitiu uma forte crítica à proposta de designação do russo como língua oficial, alegando a frágil relação histórica entre Rússia e Moldávia e a ameaça de que, dessa forma, o país tornaria ao status pré-1989, no qual o russo era predominante e a língua das comunicações. No tocante a essa situação, Steven Roper (2006, p. 190) salienta que "[...] o medo combinado com as iminentes restrições da União Europeia sobre o viajante moldavo, criaram uma enorme demanda pelos passaportes romenos".

A este temor uniu-se o fato que a União Europeia em 2001 havia solicitado que o governo romeno exigisse de todos os viajantes moldavos a apresentação de um passaporte internacional válido, imposição que causou preocupação sobre o eventual bloqueio das fronteiras romenas, tal qual o fechamento ocorrido durante o período soviético, determinando um aumento vertiginoso das solicitações da nacionalidade romena por parte dos moldavos. A questão ganhou ainda mais relevância em 2003, quando o Parlamento moldavo aprovou uma reforma na lei que passou a permitir a titularidade de dupla nacionalidade.

Diante desta desenfreada "corrida" à naturalização e das preocupações do governo moldavo quanto à manutenção da sua soberania, foram tomadas algumas medidas, dentre as quais se destaca a promulgação uma nova lei sobre o estatuto dos funcionários públicos, adotada em 2007, que passou a excluir o acesso aos cargos públicos dos moldavos que possuíssem dupla nacionalidade ou que residissem no exterior. De acordo com 
Steven Roper (2006, p. 190), trata-se de uma tentativa de reduzir o número de naturalizações estrangeiras, eliminar os conflitos de interesses com outros Estados e consolidar a soberania do país. Todavia, a Corte Europeia de Diretos Humanos, no julgamento do caso Tanase 1 em 2010, decidiu que a Moldávia deveria rever tal legislação a fim de permitir àqueles que possuíssem dupla nacionalidade a possibilidade de ocupar cargos públicos, bem como de concorrer às eleições.

Tendo em vista tal situação, o Parlamento Europeu foi ativado por meio de perguntas parlamentares à Comissão acerca, por exemplo, do reconhecimento da nacionalidade romena aos habitantes de língua romena, pertencentes à República Moldava e as consequências dessa concessão para a Moldávia, à Romênia e à União Europeia ${ }^{2}$; da adesão da Romênia à União Europeia e as relações de tal país com a Moldávia ${ }^{3}$; bem como do temor que a "permeabilidade" da fronteira entre Romênia e Moldávia pudesse levar a um aumento do ingresso de pessoas de modo ilegal, já que tal região limítrofe representa igualmente um perímetro externo da própria União Europeia ${ }^{4}$. Em resposta a este último quesito, a Comissão afirmou que a disciplina em matéria de nacionalidade entra na esfera de competência de cada Estado-membro e que a Comissão, por sua vez, considera-se incompetente para comentar a situação da emissão dos passaportes romenos.

Todavia, em resposta a uma ulterior pergunta parlamentar sobre questão análoga que ocorre na Bulgária ${ }^{5}$ - onde diariamente, segundo o eurodeputado Auke Zijlstra, umas duzentas pessoas oriundas da Macedónia, da Moldávia e da Ucrânia, batem ansiosamente à porta da Direção

1 CEDH, Grande Camera, Tanase and Chirtoaca v. Moldova, n. 7/08, julgado em 24 de abril de 2010 .

2 Pergunta escrita de Erik Meijer (GUE/NGL) à Comissão, em 26 de outubro de 2006.

3 Pergunta oral H-0811/06 de Danutė Budreikaitė para o período de perguntas da sessão de outubro de 2006, apresentada nos termos do artigo 109 do Regimento à Comissão em 19 de setembro de 2006. Salienta-se que esta pergunta não foi respondida pela Comissão. 4 Pergunta escrita E-3784/2010 de Andreas Mölzer (NI) à Comissão em 27 de maio de 2010.

5 Pergunta escrita E-012058/2011 de Auke Zijlstra (NI) à Comissão em 20 de dezembro de 2011 . 
da Nacionalidade Búlgara, em Sófia, a fim de solicitarem o passaporte búlgaro, desde que, pura e simplesmente, elas possam demonstrar ser originalmente de descendência búlgara -, a Comissão, fazendo referência ao acórdão Rottmann", adicionou que "[...] as condições para a obtenção e perda da nacionalidade dos Estados-membros são regulamentadas pela lei nacional de cada Estado membro, no respeito ao direito da União"7.

Nesta última ocasião, portanto, a Comissão foi um pouco além da tradicional postura de neutralidade e sustentou a necessidade de os Estados-membros respeitarem o direito da União ao disciplinarem as questões atinentes à escolha dos critérios de atribuição e de perda das suas nacionalidades. A diferença pode parecer sutil, mas tem fortes implicações práticas, tendo em vista que se está perante uma limitação de cunho jurídico, ainda que genericamente explicitada, da competência dos entes estatais no tocante à definição dos contornos desta matéria tão sensível como é a da nacionalidade.

Muito embora as inúmeras perguntas dirigidas à Comissão por parte do Parlamento Europeu, nenhuma postura concreta foi tomada pelas instituições europeias. Não tendo recebido nenhuma advertência formal sobre a situação além daquelas de conotação meramente política, a Romênia, nos últimos anos, tem intensificado as políticas de facilitação da abertura do processo de naturalização, ocasionando o aumento do número de nacionais moldavos que adquirem a nacionalidade romena. Na prática, todavia, o procedimento burocrático ainda é muito lento, dado que a Lei n. 171 concernente à aprovação do GEO n. 147/2008, publicada em 14 de maio de 2009, prevê a concessão do limite máximo de 30 mil naturalizações por ano. Do exposto, Constantin Iordachi (2013) deduz que no geral, a legislação sobre a reaquisição da nacionalidade romena foi extremamente expansiva, embora legalmente ambígua. De fato, a imprecisão de certas disposições torna o próprio texto criticável do ponto de vista jurídico.

Orientados pela política que permite a concessão da dupla nacionalidade com base em critérios puramente étnicos, e com isso alcançando

\footnotetext{
6 Acórdão do TJUE, C-135/08, julgado em 2 de março de 2010, Rottmann.

7 Cursivo nosso.
} 
indivíduos que residem fora do território do Estado, vários outros países do Leste europeu seguiram a mesma iniciativa romena, tais como a Bulgária (artigos 26 a 28 da Lei sobre a nacionalidade, com alterações de 19 de fevereiro de 2013) e a Hungria (Lei sobre a dupla nacionalidade em vigor desde $1^{\circ}$ de janeiro de 2011). Além disso, no âmbito do Parlamento Europeu, esta última lei foi objeto de Pergunta Parlamentar elaborada à Comissão ${ }^{8}$, na qual o eurodeputado Jaroslav Paška afirma que, de acordo com informações veiculadas pelos meios de comunicação ucranianos, o Consulado da Hungria em Berehove teria aberto um gabinete especial onde, de meia em meia hora, um cidadão ucraniano requer a emissão de um passaporte húngaro, sendo que os requisitos exigidos seriam mínimos: bastaria indicar conhecimentos da língua húngara e fazer referência a "raízes húngaras". Em resposta ao questionamento sobre quais medidas pretende a União Europeia tomar, e quando, a fim de eliminar os efeitos indesejáveis da lei húngara em matéria de dupla nacionalidade, a Comissão reafirmou a sua incompetência em relação às questões que envolvam a atribuição da nacionalidade por parte de um dos Estados-membros.

Sob a perspectiva mais abrangente do processo de integração regional europeu, pode-se dizer que a atribuição da nacionalidade à luz dos critérios utilizados por países como a Romênia e a Bulgária possui duas finalidades distintas. Do ponto de vista político, a atitude de tais Estados visa expandir e consolidar o poder geopolítico na região, afastando-a do campo de ação russo. Por outro lado, segundo uma perspectiva jurídica, a finalidade última dessas opções legislativas é compartilhar os benefícios e as prerrogativas que esses países gozam como Estados-membros da União, em particular, por meio da atribuição do status de cidadão europeu a tais indivíduos.

Certamente, ao emitir o passaporte europeu a estes indivíduos, concede-se igualmente a posse de um estatuto jurídico composto por inúmeros direitos, tais como o direito de liberdade de circulação e residência, eleitorado ativo e passivo às eleições europeias e àquelas municipais, proteção diplomática e consular, petição ao Parlamento Europeu e denúncia

8 Perguntas escritas P-3549/2011 e P-3475/2011 de Jaroslav Paška (EFD), respectivamente, ao Conselho e à Comissão, ambas de 11 de abril de 2011. 
ao Provedor de Justiça e direito de iniciativa cidadã (MOURA, 2013) e, com isso, uma posição muito vantajosa dentro de todo o espaço europeu. Pode-se, ademais, verificar na práxis o interesse de muitos estrangeiros em se tornarem titulares do status de cidadão europeu. A título exemplificativo, destaca-se que o número dos pedidos de reconhecimento da nacionalidade polonesa aumentou quase cinco vezes no momento da adesão da Polônia à União Europeia no ano de 2004. Do mesmo modo, na Itália, o número de matrimônios entre italianos e nacionais romenos diminuiu drasticamente após a adesão da Romênia à União em 2007, demonstrando que o interesse principal não era a nacionalidade italiana adquirida através do casamento, mas o status de cidadão europeu (KOCHENOV, 2010).

Os reiterados pronunciamentos do Tribunal de Justiça da União Europeia ${ }^{9}$ corroboram o entendimento de que os efeitos jurídicos das legislações estatais em matéria de nacionalidade podem de alguma maneira tocar a esfera supranacional. Assim, torna-se plausível fazer uma breve alusão a alguns princípios do direito da União Europeia com a finalidade de avaliar a (des)conformidade destes eventuais efeitos com os princípios norteadores da interpretação e da aplicação das normas europeias.

A relação entre a União, como instituição supranacional, e os Estados-membros, países que voluntariamente aderiram a este processo, é regulada por alguns princípios que visam nortear o bom andamento do fenômeno integracionista. No tocante à questão ora em análise, destacam-se dois princípios que, em um primeiro momento, podem parecer conflituosos, mas que devem ser interpretados harmoniosamente a fim de que a dimensão teleológica de integração possa prevalecer.

O primeiro deles é o princípio da leal cooperação, em virtude do qual "a União e os Estados-Membros respeitam-se e assistem-se mutuamente no cumprimento das missões decorrentes dos Tratados", sendo previsto no artigo 4, parágrafo $3^{\circ}$ do Tratado da União Europeia. O que deve imperar é o espírito de confiança recíproca e o rigoroso respeito das disposições pertinentes contidas nos tratados. Seria difícil para a União

\footnotetext{
9 Acórdãos do TJUE: C-369/90 de $1^{\circ}$ dezembro de 1990, Micheletti; C-135/08, de 2 de março de 2010, Rottmann; C-34/09 de 8 de março de 2011, Zambrano; C-434/09 de 5 de maio de 2011, McCarthy, dentre outros.
} 
cumprir de modo eficaz a sua função se o princípio da leal cooperação, que implica que os Estados-membros adotem todas as medidas necessárias, gerais ou especiais, adequadas a assegurar a execução das suas obrigações derivadas do direito comunitário ${ }^{10}$, não se impusesse no âmbito da atribuição da nacionalidade estatal, uma vez que esta comporta a automática aquisição da cidadania europeia.

Sob tal perspectiva, é claro que uma política de atribuição da nacionalidade de modo desenfreado e sem a observância dos princípios supranacionais pode ocasionar efeitos indesejáveis nos ordenamentos e nas políticas dos outros Estados-membros. De fato,

[...] o tipo de situação que poderia resultar em uma violação das obrigações previstas pelo direito da União Europeia poderia se dar quando fossem constatadas naturalizações de massa de indivíduos originários de Estados terceiros sem uma consulta prévia dos parceiros da União. (SHAW, 2011, p. 2)

No caso específico da Romênia, o governo italiano demonstrou expressamente sua preocupação com relação às medidas que tornaram possíveis a recuperação da nacionalidade romena por parte de tantos nacionais da Moldávia ${ }^{11}$. Tal comportamento reflete o interesse dos Estados-membros em limitar o número de indivíduos que, ao adquirirem a nacionalidade de um destes Estados, obtenham o direito à liberdade de circulação e residência no território de qualquer um dos 28 países hoje pertencentes ao bloco de integração regional europeu (CLERICI, 2013).

O segundo princípio referenciado é aquele consagrado no artigo 4, parágrafo $2^{\circ}$ do Tratado sobre a União Europeia. De acordo com a sua redação, a União deve respeitar a igualdade dos Estados-membros perante os tratados ao mesmo tempo em que admite a diversidade das identi-

\footnotetext{
10 Acórdão do TJUE, C-105/03 de 16 de junho de 2005, Pupino.

11 Departamento de Políticas Europeias da Presidência do Conselho de Ministros da Itália. Moldova, Ronchi: "Preoccupazione su cittadinanza romena a moldavi", de 23 de abril de 2009. Disponível em: <http://www.politichecomunitarie.it/comunicazione/16576/ moldova-ronchi-preoccupazione-su-cittadinanza-romena-a-moldavi91>. Acesso em: 5 out. 2013.
} 
dades nacionais refletidas nas suas estruturas políticas e constitucionais, incluindo a autonomia local e regional. Assim, é também verdade que a União não pode deixar de respeitar as identidades nacionais que se exprimem através das mais variadas modalidades de relação entre o instituto jurídico da nacionalidade e as ligações, por vezes históricas e étnicas, com determinados Estados terceiros.

Por tal razão, como visto, em diversas oportunidades a Comissão declarou a sua incompetência para pronunciar qualquer comentário acerca da disciplina referente às questões relativas aos critérios de atribuição e de perda da nacionalidade elaborados por qualquer Estado-membro. De qualquer modo, as numerosas perguntas parlamentares e as manifestações de cunho político de alguns países, demonstram a preocupação com a expansão deste tipo de política que visa naturalizar em massa extracomunitários.

\section{A "venda" da Nacionalidade por Parte de Estados-membros da União Europeia Como Meio de Combate à Crise Econômica}

Com a finalidade de complementar o estudo até então proposto, mostra-se oportuno igualmente acenar algumas situações em que as legislações de outros países europeus estabeleceram formas de concessão da nacionalidade a determinados estrangeiros que se mostram um tanto quanto questionáveis do ponto de vista jurídico e de conveniência política. Nesse sentido, destacam-se os recentes programas adotados por alguns países da União Europeia que, perante a crise econômica que aflige a região, têm facilitado o procedimento de atribuição das suas nacionalidades em troca de investimentos estrangeiros ou mesmo da mera "venda" da nacionalidade mediante o pagamento de uma soma em dinheiro. Certamente, são situações diferentes daquelas observadas na hipótese da "naturalização de massa" romena, mas se apresentam igualmente problemáticas em razão dos tênues vínculos de ligação do indivíduo com o Estado.

No tocante às recentes reformas de legislações nacionais de alguns Estados-membros da União Europeia no sentido de permitir a "venda" da sua nacionalidade, um dos casos mais em voga atualmente é aquele 
do pequeno arquipélago de Malta localizado no Mar Mediterrâneo e dotado de um população de pouco mais de 400 mil habitantes. Por meio de um reforma na lei sobre a nacionalidade, ocorrida em 12 de novembro de $2013^{12}$, o país passou a prever a possibilidade de o interessado obter a nacionalidade maltês por meio de pagamento de uma "taxa" no valor de 650 mil euros em favor do Fundo para o Desenvolvimento Nacional do país, já o cônjuge e os filhos menores de idade devem, por sua vez, efetuar o pagamento de apenas 250 mil euros. Desde a entrada em vigor da nova lei, mais de 200 pedidos foram protocolados no governo maltês, representando mais de 30 nacionalidades diferentes (MCDONALD, 2014).

Diante da particularidade desta situação, inúmeras foram as Perguntas Parlamentares formuladas por eurodeputados de diversos grupos políticos a fim de que a Comissão e o Conselho se pronunciassem a respeito $^{13}$. Todas as interrogações convergem no sentido de que as decisões sobre questões de nacionalidade e cidadania sejam da exclusiva competência dos Estados/membros, mas afirmam que a decisão de Malta é problemática, pois permite que novos cidadãos viajem na União e tenham acesso ao resto do espaço Schengen, sem que os outros Estados-membros tenham sido consultados. Desse modo, na visão dos eurodeputados, tal atitude pode ser interpretada como um abuso dos direitos que o país adquiriu por meio de sua adesão e como uma falta de respeito para com os outros Estados. Além disso, eles também alegam que a adoção desta política pode causar eventuais discriminações, dado que somente os estrangeiros mais ricos poderão comprar a nacionalidade maltês, bem como

\footnotetext{
12 Capítulo 188 da Lei sobre a nacionalidade maltês.

13 Perguntas escritas O-145/2013 e O-144/2013 de Judith Sargentini, Raül Romeva i Rueda, Jan Philipp Albrecht, Hélène Flautre, Franziska Keller, Ulrike Lunacek, Jean Lambert, em nome do Grupo Verts/ALE, respectivamente, à Comissão e ao Conselho, ambas em 06 de dezembro de 2013; Perguntas escritas O-138/2013 e O-137/2013 de Jan Mulder, Renate Weber, Sonia Alfano, Jens Rohde, Cecilia Wikström, Nils Torvalds, Leonidas Donskis, Alexander Graf Lambsdorff, Sir Graham Watson, Louis Michel, Nathalie Griesbeck, Sylvie Goulard, Ramon Tremosa i Balcells, Marielle de Sarnez, Jelko Kacin, Olle Schmidt, em nome do Grupo ALDE respectivamente, à Comissão e ao Conselho, ambas em 04 de dezembro de 2013; Perguntas escritas O-135/2013 e O-134/2013 Manfred Weber, Véronique Mathieu Houillon, em nome do Grupo PPE, respectivamente, à Comissão e ao Conselho, ambas em 29 de novembro de 2013.
} 
pôr em risco o próprio conceito de cidadania europeia. Ocorre que, estranhamente, a Comissão nem o Conselho pronunciaram-se sobre o assunto, não tendo ainda respondido a nenhuma das perguntas formuladas pelos eurodeputados no final de 2013.

Na mesma linha de reforma legislativa, a Bulgária, com a modificação da sua lei nacional em $2013^{14}$, passou a prever a atribuição da nacionalidade búlgara aos interessados que, dentre outras possibilidades, invistam pelo menos 512 mil euros de capital em uma empresa do país e mantenham o investimento por no mínimo três anos. Transcorrido o segundo ano, a nacionalidade é concedida. Com a intenção de facilitar o acesso às informações acerca do procedimento solicitado, o governo búlgaro dispõe de um site oficial destinado à captura dos potenciais investidores ${ }^{15}$.

Por sua vez, podem obter a nacionalidade do Chipre os interessados que efetuarem um investimento de ao menos 2 milhões de euros ou que comprarem um bem imóvel no valor de 500 mil euros ${ }^{16}$. O governo do Chipre também possui um site na internet com todas as informações a respeito da aquisição da chamada "Nacionalidade por Investimento" 17 . Interessante notar que os rumores acerca da concessão a título excepcional da nacionalidade cipriota a qualquer indivíduo estrangeiro que depositasse uma importante soma de euros num banco cipriota já havia sido levantada antes mesmo da alteração da lei em 2013, por meio de Pergunta Parlamentar encaminhada à Comissão ${ }^{18}$.

Além destes países, é possível citar as políticas do mesmo tipo adotadas por Portugal ${ }^{19}$, o qual criou, em outubro de 2012, a chamada "Autorização de Residência para atividade de investimento" ou "visto doura-

\footnotetext{
14 As alterações ao "Bulgarian Citizenship Act" e ao "Foreigners in the Republic of Bulgaria Act" entraram em vigor em 23 de fevereiro de 2013.

15 Site do governo búlgaro: <http://www.investbulgaria.eu/a/en/home.html>.

16 Seção 111- A da Lei de registro civil, de 24 de maio de 2013.

17 Site do governo cipriota: <http://www.investcyprus.org.cy/citizenship-by-investing/>

18 Pergunta escrita E-3203/2011 de Graham Watson (ALDE) à Comissão, em 31 de março de 2011.

19 Art. 90-A da Lei n. 23/2007 sobre o regime jurídico de entrada, permanência, saída e afastamento de estrangeiros do território nacional, alterada pela Lei n. 29/2012 de 9 de agosto de 2012.
} 
do", destinado aos nacionais de países terceiros. Com base nesta lei, em 2013, Portugal emitiu 471 desses vistos por conta de 306,7 milhões de euros investidos no país, $80 \%$ dos quais concedidos a cidadãos chineses ${ }^{20}$. Os requisitos para a obtenção do "visto dourado" é que o estrangeiro, pessoalmente ou através de uma sociedade, invista em Portugal, por um período mínimo de cinco anos, um montante igual ou superior a um milhão de euros ou gere pelo menos dez postos de trabalho. É possível ainda que ao invés de investir na qualidade de empresário no país, o estrangeiro simplesmente compre imóveis num valor mínimo de 500 mil euros. Este visto autoriza o investidor de um país terceiro a circular livremente no espaço Schengen, a trabalhar sem restrições e a se beneficiar do direito de reagrupamento familiar. Depois de cinco anos com o "visto dourado" os estrangeiros podem candidatar-se à cidadania portuguesa e obtê-la ao fim do sexto ano.

As indagações formuladas pelos eurodeputados à Comissão e ao Conselho $^{21}$ são no sentido de que este sistema de atribuição de "vistos dourados" pode pôr em risco os direitos e obrigações da cidadania europeia e a segurança no Espaço Schengen, originando um esquema de venda da nacionalidade a prazo e fomentando uma situação de desigualdade no tratamento de nacionais de países terceiros desejosos de aceder ao espaço europeu, mas sem avultados recursos financeiros. Em resposta, a Comissão afirmou que não existem normas harmonizadas no direito da União acerca da concessão de residência a investidores estrangeiros provenientes de Estados terceiros e, por isso, Portugal possui competência para determinar as suas regras nacionais em relação aos vistos de longa duração e às autorizações de residência. No mais, a concessão da residência em Portugal não confere, por si só, o direito destes indivíduos de residirem em outro Estado-membro, já que, segundo o artigo 21 do Acordo de Schengen, a eles é permitida a livre circulação durante um período

20 Pergunta escrita P-641/2014 de Ana Gomes (S\&D) à Comissão em 23 de janeiro de 2014.

21 Pergunta escrita P-641/2014 de Ana Gomes (S\&D) à Comissão em 23 de janeiro de 2014; Pergunta escrita P-462/2013 de Auke Zijlstra (NI) à Comissão em 17 de janeiro de 2013. 
A "naturalização de massa" na Romênia e a "venda" da Nacionalidade de Estados-membros da União Europeia: reflexões sobre o uso político e econômico do instituto jurídico da nacionalidade

máximo de três meses no território das outras Partes Contratantes e não a residência.

Da mesma forma, para ter direito a nacionalidade da Áustria, país da Europa Central com cerca de 8 milhões de habitantes, o investimento mínimo que deve ser efetuado pelo cidadão estrangeiro interessado é de 2 milhões de euros em doações para instituições de caridade ou faça um investimento de no mínimo 10 milhões de dólares na economia austríaca. ${ }^{22}$. O governo da Áustria também possui um site com as informações sobre a atribuição da "Austria Citizenship for Wealthy Investitors", no qual anuncia que o interessado não precisa ter conhecimento da língua alemã, que o passaporte austríaco tem uma excelente reputação e reconhecido em todo o mundo e que o mesmo se tornará cidadão da União Europeia quando receber a nacionalidade, sendo possível, inclusive, submeter o pedido de forma online e $^{23}$. As despesas administrativas relativas ao procedimento devem ser pagas em forma de imposto ao governo, cujo valor varia de 400 mil a 600 mil euros.

Por sua vez, Espanha e Reino Unido concedem a residência aos investidores estrangeiros, mas por ora, sem a atribuição das respectivas nacionalidades. Na Espanha, em setembro de 2013 foi promulgada uma lei de apoio aos empreendedores e sobre internacionalização que disciplina a concessão de um visto de residência para o indivíduo que tenha comprado um bem imóvel cujo valor fosse de ao menos 500 mil euros ou tenha realizado um investimento de no mínimo um milhão de euros no país ${ }^{24}$. Por sua vez, no Reino Unido, as alterações introduzidas em 13 de dezembro de 2012 à "Part 6 A of the Immigration Rules" preveem que o interessado deva investir ao menos de 1 milhão de esterlinas no Reino Unido para obter o visto de residência permanente ${ }^{25}$.

Tendo em vista tal situação, alguns eurodeputados manifestaram suas preocupações quanto às políticas de naturalização adotadas por cer-

${ }^{22}$ Art. 10, par. 6 da Lei austríaca sobre a nacionalidade.

23 Site do governo da Áustria: < http://www.austria-citizenship.com/>.

24 Art. 63 a 67 da Lei n. 14/2013 "de apoyo a los emprendedores y su internacionalización" de 27 de setembro de 2013.

25 "Part 6 A of the Immigration Rules" com as modificações de 13 de dezmebro de 2012. 
tos países. Nas perguntas parlamentares do deputado Graham Watson ${ }^{26}$, ele afirma ter conhecimento da posição reiterada da Comissão em se manter em uma posição de neutralidade quanto às condições de obtenção e perda de cidadania de um Estado-Membro, uma vez que seriam determinadas exclusivamente por cada lei nacional. Embora isso possa ser verdade, o eurodeputado pergunta ao Conselho e à Comissão se não seria plausível concordar que, no contexto do artigo $4^{\circ}$ do Tratado da União Europeia, que impõe aos Estados-Membros o dever de cooperarem com a União e entre si, e tendo em conta o princípio da liberdade de circulação das pessoas na União Europeia, uma política envolvendo a naturalização em massa de nacionais de países terceiros poderia ter graves implicações para outros Estados-membros. Curioso que, em ambas as respostas oferecidas, tanto o Conselho quanto a Comissão informam não tinham conhecimento de políticas nacionais implementadas por Estados-membros da União Europeia no sentido de atualmente procederem a naturalizações em massa ou à atribuição da nacionalidade a título excepcional a quem deposite certo montante em dinheiro num banco nacional.

Mais recentemente, e diante de grande pressão política, a Comissão, em resposta a uma Pergunta Parlamentar ${ }^{27}$, reconheceu que desde o Tratado de Maastricht, a atribuição da nacionalidade de um Estado-membro significa também a concessão da cidadania da União e, por consequência, de importantes direitos suplementares. As decisões sobre naturalização de um Estado-membro não são, portanto, neutras em relação aos outros Estados e à União. Afirmou, ainda, que espera que os Estados-membros utilizem as suas prerrogativas de concessão da nacionalidade na observância do espírito de sincera cooperação com os outros Estados-membros e com a União e, para tanto, precisavam igualmente levar em consideração as normas e as obrigações que estão sujeitos no âmbito do direito internacional. Após uma série de contatos com as autoridades maltesas, a Comissão afirmou que, neste caso, serão realizadas modificações na lei sobre a nacionalidade deste país, introduzindo

26 Perguntas escritas E-6519/2011 e E-6520/2011 de Graham Watson (ALDE), respectivamente, ao Conselho e à Comissão, ambas de 11 de julho de 2011 .

27 Pergunta escrita E-13318/2013 de Andreas Mölzer (NI) à Comissão de 25 de novembro de 2013. 
A "naturalização de massa" na Romênia e a "venda" da Nacionalidade de Estados-membros da União Europeia: reflexões sobre o uso político e econômico do instituto jurídico da nacionalidade

o requisito da "conexão efetiva", concretizado por meio da residência efetiva em Malta por no mínimo 12 meses.

À luz do direito internacional, a condição da "conexão efetiva" com o país no qual se obteve a naturalização é imprescindível para que a nacionalidade adquirida possa ser oponível a outros Estados para fins, por exemplo, de proteção diplomática. Caso contrário, não será considerada uma modalidade válida além das fronteiras estatais, conforme entendimento adotado no peculiar acórdão Nottebohm ${ }^{28}$ da Corte Internacional de Justiça (WEIS, 1979, p. 180).

\section{Conclusão}

Os institutos da cidadania e da nacionalidade parecem adquirir novos contornos não somente em razão do surgimento da cidadania da União europeia, sui generis na sua essência, mas também se levar em consideração os mais recentes fenômenos observados na condução de políticas estatais voltadas a reformar as tradicionais legislações sobre nacionalidade com o escopo de introduzir inusitados critérios para a atribuição do status civitatis aos estrangeiros interessados.

As "naturalizações de massa" são fenômenos de certo modo recorrentes na história, inclusive naquela do Brasil do século XIX, e sempre geraram debates e vultuosas críticas em razão das peculiaridades inerentes a esta forma de atribuição da nacionalidade. No caso particular da Romênia a situação mostra-se ainda mais delicada pelo fato de esta ser membro de uma organização internacional supranacional que, por sua vez, também concede um tipo de cidadania detentora de um estatuto jurídico invejável por muitos extracomunitários.

Percebe-se que uma das principais motivações para a adoção de uma legislação mais flexível e abrangente no tocante à atribuição da nacionalidade pelo governo romeno é, de um lado, a sua restituição para aqueles indivíduos que faziam parte da Grande Romênia no passado e que, por razões históricas, perderam o gozo de tal status. No plano polí-

28 CIJ, Liechtenstein v. Guatemala, caso Nottebohm de 6 de abril de 1955. 
tico, todavia, depreende-se que a motivação é outra. A vontade de afastar definitivamente a influência russa e conseguir dominar geopoliticamente a região é a preocupação fundamental que sustenta o projeto de levar a nacionalidade romena para todos os interessados.

Considerando, dessa forma, a análise desenvolvida ao longo do presente estudo, acredita-se que a política de naturalização dita "de massa", verificada na Romênia, não parece violar princípios supranacionais, pois existem fatores históricos e étnicos capazes de proporcionar uma consistente ligação entre os naturalizados e o Estado romeno. Os únicos fatores de vulnerabilidade são a inegável influência ocasionada pelos fluxos migratórios em outros Estados-membros e a consequente concessão de inúmeros direitos previstos no estatuto pessoal do cidadão europeu, que extrapolam os limites de jurisdição da Romênia e alcançam aquele da União.

Diferente, no entanto, se apresenta a questão referente ao fenômeno que vem ocorrendo em vários países europeus, nos quais se passou a permitir a "compra" da nacionalidade. A emissão da autorização de residência temporária para extracomunitários que invistam em bens imobiliários e injetem diretamente dinheiro na economia ou nos cofres públicos do governo, estão geralmente acompanhadas de posterior transformação daquela em residência permanente e, até mesmo, da atribuição da nacionalidade. Países como Áustria, Portugal, Malta, Bulgária e Chipre executam uma política conhecida como "cidadania por investimento", oferecendo-a a quem tiver interesse, e condições financeiras, de adquiri-la. Por sua vez, alguns Estados apenas concedem o visto de residente permanente aos investidores, sem, por ora, ofertar a sua nacionalidade, como é o caso da Espanha e do Reino Unido.

Notória é a extensão e a profundidade da crise econômica que assola a Europa nos últimos anos, bem como a dificuldade de os países se recuperarem dos prejuízos por ela ocasionados. Mas seria esta uma alternativa viável e lícita para tentar contornar a crise? É possível afirmar que a concessão de autorizações de residência no espaço Schengen se tornou um modelo lucrativo de negócio colocado em prática pelas autoridades de alguns países? O fato incontestável é que o número de autorizações emi- 
tidas sob a égide de tais programas está aumentando rapidamente, assim como o número de Estados-membros partidários de tal escolha legislativa, o que vem preocupando as instituições supranacionais.

As manifestações de cunho político contestando a legitimidade destas iniciativas tiverem origem, predominantemente, no Parlamento Europeu. As consultas encaminhadas à Comissão e ao Conselho sempre confirmavam a competência exclusiva dos Estados-membros nesta matéria, mas em um dos últimos pronunciamentos foi sinalizada uma mudança de comportamento. A Comissão, como analisado, solicitou a introdução do requisito da "conexão efetiva" na lei maltesa, o qual pode ser concretizado através da residência efetiva do interessado no território do país em que pretende adquirir a naturalização. No entanto, a resposta dos comissários refere-se a um caso específico, o de Malta, não implicando um comprometimento direto dos demais Estados em igualmente observá-la no sentido de proceder com as devidas modificações legislativas.

Percebe-se, portanto, que se está diante de uma grave violação tanto do ordenamento jurídico internacional quanto do próprio direito da União. A atribuição da nacionalidade por estes Estados não observa os princípios norteadores do instituto jurídico da nacionalidade ao criar um novo critério de concessão baseado exclusivamente no fator "dinheiro". A utilização do mesmo para fins explicitamente econômicos precisa ser revista urgentemente pelas autoridades competentes e pelos juízes de Luxemburgo, a fim de que se possa dar uma clara orientação acerca dos limites de ordem internacional e comunitária aos quais estão submetidos os Estados-membros ao exercessem o seu poder soberano na disciplina desta matéria.

\section{Referências}

AKAN, Simon. New York Times: Spain Gives Citizenship to a Fighter of Franco. Publicado em 26 de agosto de 2009. Disponível em: <http:// www.nytimes.com/2009/08/27/nyregion/27lincoln.html?th\&emc=th $>$. Acesso em: 20 set. 2013. 
BOLL, Alfred Michael. Multiple Nationality and International Law. Leiden-Boston: Martinus Nijhoff Publishers, 2007.

CLERICI, Roberta. Freedom of States to Regulate Nationality: European versus International Court of Justice? In: BOSCHIERO, Nerina et al. (Ed.). International Courts and the Development. The Hague: Asser Press, 2013. p. 839-862.

DOLINGER, Jacob. Direito internacional privado (parte geral). 4. ed. Rio de Janeiro: Renovar, 1997.

IORDACHI, Constantin. Romania Country Report: EUDO Citizenship Observatory. San Domenico di Fiesole: European University Institute, 2013. p. 2 ss.

KÁNTOR, Zoltán. The status law syndrome and regional/national identity: hungary, hungarians in Romania, and Romania. In: IEDA, Osamu; UYAMA, Tomohiko (Ed.). Reconstruction and interaction of Slavic Eurasia and its neighboring worlds. Sapporo: Slavic Research Center Hokkaido University. 2006.

KOCHENOV, Dimitry. Rounding up the circle: the mutation of Member States' nationalities under pressure from EU Citizenship. In: EUI WORKING PAPERS. RSCAS 2010/23. San Domenico di Fiesole: European University Institute, 2010. p. 21.

LIEBICH, Andre. Introduction. In: BAUBÖCK, Rainer; PERCHINIG, Bernhard; SIEVERS, Wiebke (Ed.). Citizenship Policies in the new Europe. Amsterdam: Amsterdam University Press, 2007.

LEONCINI, Francesco. Tra passato e presente: la Romania nell'Europa Centrale. In: ROMANIA, TURCHIA E NUOVI EUROPEI. Europa e regione - collana di studi, saggi e documentazioni. Pordenone: IRSE, 2007.

MAKAROV, Alexander Nikolajevie. Règles Générales du Droit de la Nationalité. Académie de droit international de La Haye. Paris: Recueil Sirey, 1949.

MCDONALD, Vanessa. Over 200 apply for citizenship. Times of Malta. Publicado em 10 de agosto de 2014. Disponível em: < http://www. 
A "naturalização de massa" na Romênia e a "venda" da Nacionalidade de Estados-membros da União Europeia: reflexões sobre o uso político e econômico do instituto jurídico da nacionalidade

timesofmalta.com/articles/view/20140810/business-news/Over-200apply-for-citizenship.531295>. Acesso em: 13 out. 2014.

ROPER, Steven D. Education as an Istrument os Moldovan Identity Formation, In: IEDA, Osamu; UYAMA, Tomohiko (Ed.). Reconstruction and interaction of Slavic Eurasia and its neighboring worlds. Sapporo: Slavic Research Center Hokkaido University. 2006 SHAW, Jo. Setting the scene: the Rottmann case introduced. In: EUI WORKING PAPERS. RSCAR 2011/62. San Domenico di Fiesole: European University Institute, 2011. p. 2.

WEIS, Paul. Nationality and Statelessness in International Law. 2 ed. The Netherlands: Sijthoff \& Noordhoff, 1979.

Aline Beltrame de Moura é bacharel em Direito pela Universidade Federal de Santa Catarina (2008), mestre em Direito nas Relações Internacionais pela mesma instituição (2010) e doutora em Direito Internacional Público e Privado pela Università degli Studi di Milano (2014), Itália. Bolsista Capes de Doutorado Pleno no Exterior. Foi visiting researcher no Max Planck Institute for Comparative and International Private Law em Hamburgo, Alemanha (2013). Atualmente é professora substituta de Direito Civil e de Direito Internacional na Universidade Federal de Santa Catarina (UFSC) e de Mediação e Arbitragem na Faculdade CESUSC. É também professora no Curso de Pós-Graduação lato sensu em Direito Civil e Processo Civil da Faculdade Católica de Santa Catarina. É Pesquisadora do Grupo de Estudos de Direito Internacional Ius Gentium CNPQ/UFSC e Coordenadora do Grupo de Pesquisas em Direito Internacional do CESUSC. Vencedora do Prêmio Riccardo Monaco de melhor tese de doutorado na área de direito internacional defendida na Itália no ano de 2014.

E-mail: alineb.moura@gmail.com.

Endereço profissional: Universidade Federal de Santa Catarina, Centro de Ciências Jurídicas. Campus da Trindade Trindade. CEP: 88040-900 - Florianópolis, SC Brasil. 